\title{
EFEITOS DA COMPACTAÇÃO DO SOLO E DO MANEJO DA ÁGUA SOBRE OS COMPONENTES DE PRODUÇÃO E A PRODUTIVIDADE DE GRÃOS DE ARROZ
}

\author{
Effects of soil compaction and water management upon yield components and rice grain yields
}

\author{
Roberto Dantas de Medeiros ${ }^{1}$, Antônio Alves Soares², Renato Mendes Guimarães
}

\begin{abstract}
RESUMO
Conduziu-se este trabalho com o objetivo de avaliar os efeitos de diferentes níveis de compactação e manejos de água sobre os componentes de produção e a produtividade de grãos de arroz. O experimento foi conduzido no período de setembro de 2002 a janeiro de 2003 em casa- de-vegetação na UFLA, em Lavras-MG, onde se testou seis níveis de compactação do solo: 0\%, 16\%, 32\%, $48 \%, 64 \%$ e $80 \%$ da amplitude de variação da densidade do solo $\left(0,25 \mathrm{~kg} \mathrm{dm}^{-3}\right)$, combinado com três teores de água no solo: solo saturado (M1), irrigado quando eram consumidos de 25 a 30\% (M2) e de 50 a $60 \%$ (M3) da água disponível, respectivamente. Os resultados evidenciam que a compactação do solo tende a reduzir o número de panícula por vaso, a esterilidade de espiguetas e a produtividade de grãos. Em níveis moderados de compactação, houve aumento do número de grãos cheios por panícula, considerando os três manejo de água. A umidade favoreceu os componentes de produção: o número de panículas por vaso, o número de grãos cheio por panícula e a esterilidade de grãos, contribuindo para o aumento da produtividade. Assim, conclui-se que a umidade do solo foi mais determinante que a compactação como fator limitante para a produção de grãos e, que, para o Neossolo Flúvico, a compactação per si não é fator limitante a uma possível adoção do sistema de plantio direto com arroz em várzeas.
\end{abstract}

Termos para indexação: Oryza sativa, densidade do solo, umidade, adensamento.

\begin{abstract}
The work aimed at evaluating the effect of different compaction levels and water management upon yield components and rice grain yield. The experiment was conducted over the period of September 2002 to January 2003 in a greenhouse at the UFLA university, in Lavras- MG, where as tested six compaction levels: $0 \%, 16 \%, 32 \%, 48 \%, 64 \%$ and $80 \%$ of the range of variation of soil density (0.25kg.dm-3), combined with three soil water contents: saturated soil (M1), irrigated when were consumed from 25 to $30 \%$ (M2) and from 50 to $60 \%$ (M3) of available water, respectively. The results stressed that soil compaction tends to reduce the number os panicles per pot, sterility of spikelets and grain yield. At moderate compaction levels, there was an increase of the number of filled grain per panicle, taking into account the three water management. Moisture favored production components: the number of panicles per pot, the number of filled grain per panicle and spikelet sterility, contributing toward increased yield. Thus, it follows that soil moisture was more determinant than compaction as a limiting factor to grain yield and, that, for Fluvic Neosol, compaction per si is not a factor limiting to a possible adoption of the no-tillage system with lowland rice.
\end{abstract}

Index terms: Oryza sativa, soil density, moisture, compaction.

(Recebido para publicação em 7 de junho de 2004 e aprovado em 20 de julho de 2005)

\section{INTRODUÇÃO}

A partir da década de noventa, a cultura do arroz de terras altas vem perdendo espaço para o milho e a soja que têm se mostrado mais rentáveis. A situação se agravou com a adoção do sistema de plantio direto para as cultura do milho e da soja, uma vez que o arroz de sequeiro não tem se adaptado bem a esse sistema.

O desenvolvimento insatisfatório do sistema radicular devido à compactação do solo e a exigência de macroporosidade têm sido relatados como as principais causas do insucesso da adoção da prática do plantio direto no arroz de terras altas (KLUTHCOUSKI, 1998; SÉGUY et al., 1999). Por outro lado, no arroz irrigado por inundação, esse sistema vem sendo utilizado, sem restrição, com sucesso e eficácia no controle de plantas daninhas, sobretudo do arroz vermelho e preto. Dessa forma, o teor de água no solo tem sido um fator importante para o desempenho da cultura do arroz no sistema de plantio direto.

Pesquisas evidenciam que a compactação do solo reduz o volume de macroporos enquanto os microporos permanecem praticamente inalterados, diminuindo as taxas de infiltração e da condutividade hidráulica do solo (STONE et al., 2002). Isso afeta negativamente a aeração, a mineralização mais lenta da matéria orgânica, a disponibilidade e absorção de água e de nutrientes pelas plantas, o fluxo de $\mathrm{CO}_{2}$ e dos nutrientes no solo

${ }^{1}$ Pesquisador Embrapa, D.Sc em Fitotecnia - BR 174, Km 8 - Distrito Industrial - Cx. P. 133 - 69.301-970 - Boa Vista, RO - roberto@cpafrr.embrapa.br ${ }^{2}$ Engenheiro Agrônomo, D.Sc, Professor do Departamento de Agricultura da Universidade Federal de Lavras/UFLA - Cx. P. 3037 - $37.200-000$ Lavras, MG. 
(ALVARENGA et al., 1996; COSTA, 1998; RIBEIRO, 1999). Conseqüentemente diminui o desenvolvimento do sistema radicular, da parte aérea das plantas e a produtividade de grãos de arroz (GUIMARÃES \& MOREIRA, 2001; RIBEIRO et al., 2003), do feijoeiro (GUIMARÃES et al., 2002) e de braquiária (GROSS et al., 2003) devido ao aumento da resistência à penetração (HOFFMANN \& JUNGK, 1995; STONE et al., 2002) propiciada, principalmente pelo déficit hídrico (HOOQUE \& KOBATA, 2000).

Contudo, a influência da compactação sobre as plantas depende da espécie, do tipo de solo e do teor de água no solo. Diversos pesquisadores observaram que em magnitude moderada, a compactação tem proporcionado efeitos benéficos como melhoria do contato solo-semente e raiz, favorecendo a absorção de água e de nutrientes pelas plantas (SMUCKER \& ERIKSON, 1989; STIRZAKER et al., 1996). Assim, Leite et al. (2003) constataram que a compactação de até $3,0 \mathrm{~kg} \mathrm{dm}^{-3} \mathrm{em}$ um Latossolo de textura média aumentou o peso de panículas e o da matéria seca da parte aérea das plantas de arroz (MSPA). Silveira (2002) também obteve aumento de $48 \%$ na MSPA no solo sob a densidade de $1,39 \mathrm{~kg} \mathrm{dm}^{-3} \mathrm{em}$ relação à produção obtida no solo sob a densidade de 1,12 $\mathrm{kg} \mathrm{dm}^{-3}$.

Com relação ao manejo de água, o arroz requer alto teor de água no solo para o seu desenvolvimento normal $\mathrm{e}$, conseqüentemente, maior produtividade. Ao reduzir-se o conteúdo de água no solo, diminui o número de panículas (CRUSCIOL et al., 1997; RODRIGUES, 1998), o número de grãos cheios por panícula, o peso de 1000 grãos (RODRIGUES, 1998) e aumenta a esterilidade das espiguetas (YOSHIDA, 1975), refletindo em redução na produtividade de grãos (RODRIGUES, 1998; CRUSCIOL, 2001).

Por outro lado, a alta disponibilidade de água no solo diminui a resistência do solo 'a penetração das raízes (HOQUE \& KOBATA, 2000), favorece a taxa fotossintética nas folhas, a absorção de nutrientes pelas plantas, a redução e a solubilização dos óxidos de ferro (GOMES et al., 1985), incrementando o número de panícula, o peso de 1000 grãos e a produtividade de grãos (CARVALHO JUNIOR, 1987; CRUSCIOL, 2001). Porém, este efeito não depende da presença da lâmina de água sobre a superfície do solo, basta que o mesmo esteja saturado (GOMES et al., 1985).

Portanto, conduziu-se o presente trabalho com o objetivo de avaliar a cultura do arroz sob diferentes níveis de compactação de um Neossolo Flúvico, associado a diferentes manejos de água e comparar seus efeitos sobre os componentes de produção e a produtividade de grãos.

\section{MATERIAL E MÉTODOS}

O experimento foi conduzido em casa-de-vegetação do Departamento de Agricultura da Universidade Federal de Lavras - UFLA, em Lavras-MG, no período de setembro de 2002 a janeiro de 2003. Utilizou-se a cultivar de arroz de terras altas Liderança e um solo de várzea classificado como Neossolo Flúvico, coletado na profundidade de 0 a $20 \mathrm{~cm}$, que, analisado apresentou as seguintes características químicas e físicas: $\mathrm{pH}\left(\mathrm{H}_{2} 0\right)=5,7 ; \mathrm{Ca}^{2+}=4,9 \mathrm{cmol}_{\mathrm{c}} \mathrm{dm}^{-3} ; \mathrm{Mg}^{2+}$ $=1,6 \mathrm{cmol}_{\mathrm{c}} \mathrm{dm}^{-3} ; \mathrm{Al}^{3+}=0,1 \mathrm{cmol}_{\mathrm{c}} \mathrm{dm}^{-3} ; \mathrm{P}=19,4 \mathrm{mg} \mathrm{dm}^{-3} ; \mathrm{K}=$ $225,0 \mathrm{mg} \mathrm{dm}^{-3} ; \mathrm{MO}=20 \mathrm{~g} \mathrm{Kg}^{-1} ;$ areia $=80 \mathrm{~g} \mathrm{Kg}^{-1} ;$ silte $=350$ $\mathrm{g} \mathrm{kg}^{-1} ;$ argila $=570 \mathrm{~g} \mathrm{~kg}^{-1}$ (classe textural argila), determinadas segundo metodologia apresentada pela Embrapa (1997).

Os tratamentos constaram de seis níveis de compactação do solo 0\%, 16\%, 32\%, 48\%, 64\% e $80 \%$ da amplitude de variação da densidade do solo $(\Delta \mathrm{ds})$, equivalendo às densidades de solo $1,11 \mathrm{Mg} \mathrm{m}^{-3} ; 1,15 \mathrm{Mg}$ $\mathrm{m}^{-3} ; 1,19 \mathrm{Mg} \mathrm{m}^{-3} ; 1,23 \mathrm{Mg} \mathrm{m}^{-3} ; 1,27 \mathrm{Mg} \mathrm{m}^{-3}$ e $1,31 \mathrm{Mg} \mathrm{m}^{-3}$, combinados com três manejos de água no solo: $\mathrm{M} 1=$ solo saturado, isto é, $100 \%$ dos poros ocupados com água, M2 = irrigação quando eram consumidos de 25 a $30 \%$ da água disponível (AD) para as plantas e M3 = irrigação quando eram consumidos de 50 a $60 \%$ da água disponível. Considerou-se $\mathrm{AD}$, o teor de água retida no solo na tensão 0,006 MPa menos o teor de água retida no solo na tensão de $1,5 \mathrm{MPa}$.

A compactação máxima do solo foi determinada pelo teste de Procton normal, alcançando-se a densidade máxima de $1,36 \mathrm{~kg} \mathrm{dm}^{-3}$ com $26 \%$ de umidade. Determinou-se a amplitude de variação da densidade do solo ( $\Delta$ ds) através da expressão: $\Delta \mathrm{ds}=$ densidade máxima $\left(1,36 \mathrm{~kg} \mathrm{dm}^{-3}\right)$ densidade mínima observada no campo $\left(1,11 \mathrm{~kg} \mathrm{dm}^{-3}\right)=$ $0,25 \mathrm{~kg} \mathrm{dm}^{-3}$.

Cálculo das densidades do solo:

Nível 0: $0 \%$ da $\Delta$ ds = a densidade mínima do solo sem compactação $=1,11 \mathrm{~kg} \mathrm{dm}^{-3}$.

Nível 1: $16 \%$ da $\Delta$ ds e as demais densidades foram determinadas por regra de três simples:

$0,25-100 \mathrm{x}=(0,25 \mathrm{x} 16) / 100=0,04 \backslash \mathrm{ds}$ a $16 \%=1,11+0,04=$ $\mathrm{x}-16, \quad 1,15 \mathrm{~kg} \mathrm{dm}^{-3}$.

Nível 2: $32 \%$ da $\Delta$ ds: $x=(0,25 \times 32) / 100=0,08 \Rightarrow 1,11+0,08=1,19$ $\mathrm{kg} \mathrm{dm}{ }^{-3}$. 
Nível 3: $48 \%$ da $\Delta$ ds: $\mathrm{x}=(0,25 \mathrm{x} 48) / 100=0,12 \Rightarrow 1,11+0,12=1,23$ $\mathrm{kg} \mathrm{dm}^{-3}$.

Nível 4: $64 \%$ da $\Delta$ ds: $\mathrm{x}=(0,25 \times \mathrm{x} 64) / 100=0,16 \Rightarrow 1,11+0,16=1,27$ $\mathrm{kg} \mathrm{dm}^{-3}$.

Nível 5: $80 \%$ da $\Delta$ ds: $\mathrm{x}=(0,25 \times 80) / 100=0,20 \Rightarrow 1,11+0,20=1,31$ $\mathrm{kg} \mathrm{dm}^{-3}$.

As parcelas foram constituídas por vasos confeccionados em tubos de PVC, com $200 \mathrm{~mm}$ de diâmetro por $35 \mathrm{~cm}$ de altura, contendo uma coluna de solo de 7,018 $\mathrm{dm}^{-3}$ (24 cm de altura x $20 \mathrm{~cm}$ de diâmetro) deixando-se uma borda livre de $11 \mathrm{~cm}$. O solo foi seco à sombra e peneirado em malha de 4,76 mm. A compactação do solo foi produzida artificialmente por meio de uma prensa hidráulica.

A adubação de plantio foi realizada antes da compactação do solo, colocando-se por vaso: $2,41 \mathrm{~g}$ de fosfato monobásico de potássio + 7,31 g de MAP + 2,15 g de sulfato de magnésio $+2,47 \mathrm{~g}$ de nitrato de cálcio e 0,50 $\mathrm{g}$ de FTE BR 13. Em cobertura, foram efetuadas três adubações: a primeira aos 25 dias após a emergência (d.a.e.), aplicando-se $0,97 \mathrm{~g}$ de nitrato de potássio $+1,74 \mathrm{~g}$ de nitrato de amônia por vaso; a segunda e a terceira foram efetuadas aos 50 e 70 d.a.e., respectivamente, aplicando-se 2,20 g de nitrato de amônia por vaso.

A semeadura foi realizada, utilizando-se oito sementes por vaso. Dez dias após a emergência das plântulas, efetuou-se o desbaste, deixando-se duas plantas por vaso. A partir daí, estabeleceu-se os tratamentos com manejo de água que foram monitorados por meio de pesagens, até o final do ciclo das plantas.

Utilizou-se o delineamento inteiramente ao acaso em esquema fatorial $6 \times 3$, sendo seis níveis de compactação do solo e três manejos de água com três repetições. Foram avaliados os números de panículas por vaso, o número de grãos cheios por panícula, a esterilidade de espiguetas, a massa de 1000 grãos e a produtividade de grãos por vaso. Os dados foram submetidos à análise de variância $(\mathrm{P} \leq 0,05)$; as médias dos efeitos do manejo de água foram comparadas pelo teste de Tukey a 5\%, e às dos níveis de compactação analisadas através de regressão polinomial, utilizando-se o programa SANEST.

\section{RESULTADOS E DISCUSSÃO}

Todas as características avaliadas foram submetidas à análise de variância, cujos resultados são apresentados na Tabela 1. Os resultados mostram que todas as características, à exceção da massa de 1000 grãos que não sofreu interferência de nenhum dos fatores e da esterilidade de espiguetas para manejo de água, foram influenciadas pela compactação e pelo manejo de água. O número de grãos cheios por panícula-1 ${ }^{-1}$ a esterilidade de espiguetas e a produtividade de grãos vaso $^{-1}$, responderam de modo diferente quando submetidos a diferentes níveis de compactação combinados com os três manejos de água.

O número de panículas por vaso obtido em função dos manejos de água encontra-se na Tabela 2 e sob os dos níveis de compactação na Figura 1. Pela Tabela 2, observase que o manejo (M1) favoreceu o número de panículas vaso $^{-1}$, superando em $19,8 \%$ o obtido sob o M2 que, por sua vez, não diferiu do M3. Esse aumento propiciado pelo M1, deve-se a maior disponibilidade e absorção de nutrientes pela plantas cultivadas no solo saturado. Esse resultado corrobora com os obtidos por Crusciol et al. (1997) e Rodrigues (1998), que também observaram aumento do número de panículas com maiores teores de água no solo.

TABELA 1 - Resumo da análise de variância para as características avaliadas, envolvendo diferentes níveis de compactação (C), manejos de água (MA) e interações.UFLA, Lavras-MG, 2004.

\begin{tabular}{|c|c|c|c|c|c|}
\hline \multirow{2}{*}{ Características avaliadas } & \multirow{2}{*}{$\begin{array}{c}\text { Média } \\
\text { geral }\end{array}$} & \multirow{2}{*}{$\mathrm{CV}(\%)$} & \multicolumn{3}{|c|}{ Quadrado médio } \\
\hline & & & $\mathbf{C}$ & MA & C x MA \\
\hline Número de panículas vaso ${ }^{-1}$ & 21,9 & 5,7 & $60,4 * *$ & $120,4 * *$ & 2,1 \\
\hline Número de grãos cheios por panícula ${ }^{-1}$ & 163,0 & 5,1 & $161,7 * *$ & $141,7 * *$ & $11,7 * *$ \\
\hline Esterilidade de espiguetas (\%) & 6,9 & 10,0 & $1,42^{*}$ & 0,41 & $2,89 * *$ \\
\hline Massa de1000 grão $(\mathrm{g})$ & 25,2 & 3,5 & 0,4 & 0,06 & 0,02 \\
\hline Produtividade de grão $\left(\mathrm{g}_{\text {vaso }}{ }^{-1}\right)$ & 89,4 & 5,5 & $997,7 * *$ & $2932,6^{* *}$ & $65,2 * *$ \\
\hline
\end{tabular}

**, * F significativo, nos níveis de $1 \%$ e $5 \%$ de probabilidade, respectivamente.

Ciênc. agrotec., Lavras, v. 29, n. 5, p. 960-967, set./out., 2005 
TABELA 2 - Número de panículas vaso ${ }^{-1}$ obtido em função de três manejos de água. UFLA, Lavras, MG, 2004.

\begin{tabular}{lc}
\hline \multicolumn{1}{c}{ Manejo de água } & Panículas.vaso $^{-1}$ \\
\hline M1 - Solo saturado & $24,9 \mathrm{a}$ \\
M2 - Irrigado quando eram consumidos de 25\% a 30\% da AD & $20,8 \mathrm{~b}$ \\
M3 - Irrigado quando eram consumidos de 50\% a 60\% da AD & $20,2 \mathrm{~b}$ \\
\hline
\end{tabular}

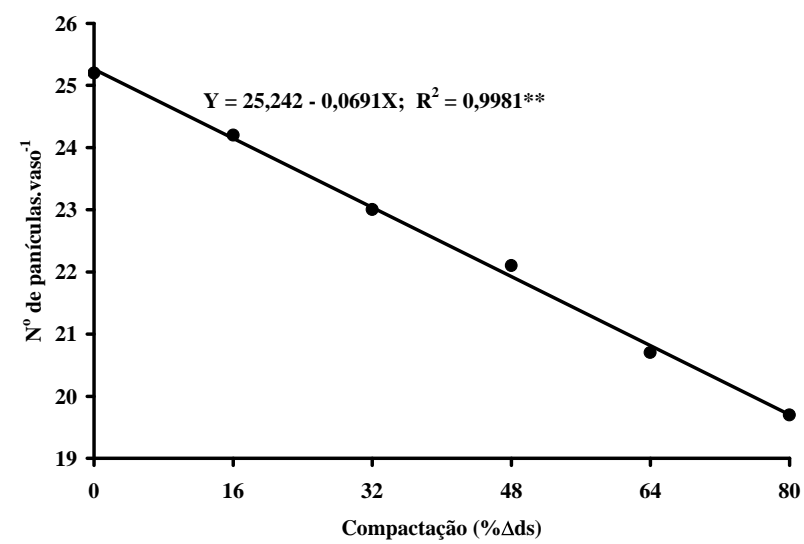

FIGURA 1 - Efeito dos níveis de compactação sobre o número de panículas vaso ${ }^{-1}$, considerando a média dos três manejos de água. UFLA, Lavras-MG, 2004.

Com relação aos níveis de compactação (Figura 1), houve decréscimo do número panículas vaso ${ }^{-1}$, de 25,2 , observado no nível zero de compactação, para 18,6 no nível máximo, equivalendo a uma redução de 26,3\%. Esse resultado concorda com os obtidos por Gross et al. (2003) e Ribeiro et al. (2003) que também observaram redução linear no número de perfilhos de arroz e de braquiária com o aumento da compactação. Essa redução justifica-se pela menor absorção de nutrientes, sobretudo de $\mathrm{N}$ que é o elemento que mais contribui para o perfilhamento e conseqüentemente, o número de panícula. A compactação limita a aeração e, por conseguinte, a mineralização da matéria orgânica, reduzindo a disponibilidade de nutrientes.

O número de grãos cheios por panícula e a esterilidade das espiguetas obtidos em função do desdobramento da interação níveis de compactação $\mathrm{x}$ manejo de água encontram-se nas Figuras 2a e 2b, respectivamente. No M1, houve aumento do número de grãos cheios por panícula à medida que se aumentou a compactação (Figura 2a). Para cada incremento de $10 \%$ na amplitude de variação da densidade do solo $(\Delta \mathrm{ds})$ correspondeu ao acréscimo de 2,49 grãos por panícula. Esse aumento está relacionado a um efeito de compensação, uma vez que a compactação reduziu o número de panículas por vaso, mas, ao mesmo tempo, não houve restrições de água, o que favoreceu a disponibilidade e a absorção de nutriente.

Nos manejos M2 e M3, a compactação aumentou o número de grãos cheios por panícula até os níveis de $24 \%$ e $30 \%$ da $\Delta$ ds, atingindo o máximo de 174 e 166 grãos panícula $^{-1}$, respectivamente. A partir desses níveis, o número de grãos por panícula diminuiu à medida que se aumentou a compactação, alcançando no nível máximo, uma redução de cerca de $14,1 \%$, para ambos os manejos. Essa redução deve-se a ocorrência de estresse hídrico com a redução da água disponível e a menor absorção de nutrientes pelas plantas, à medida que se aumentou a densidade do solo. Esse resultado foi semelhante ao relatado por Silveira et al. (2003), o qual pode ser atribuído às alterações nas características químicas e físico-hídricas do solo relatadas por Alvarenga et al. (1996), Hoque \& Kobata (2000), Ribeiro (1999) e Stone et al. (2002).

Quanto ao efeito do desdobramento da interação compactação x manejo de água sobre a esterilidade das espiguetas (Figura 2b), observa-se que nos manejos M1 e M2, ocorreram decréscimo da esterilidade com o aumento dos níveis de compactação. Os valores de esterilidade se ajustaram a um modelo de regressão linear decrescente, promovendo uma redução de 5,8\% e 7,0\% sob M1 e M2, respectivamente. No $\mathrm{M} 3$, a esterilidade aumentou à medida que se elevaram os níveis de compactação, cujos valores se ajustaram a um modelo de regressão linear crescente com coeficiente de determinação estimado em $68,9 \%$.

A redução na esterilidade de espiguetas no M1 e no M2 justifica-se pela maior disponibilidade de água e de nutrientes propiciada por esses manejos durante todo ciclo da cultura. Por outro lado, o aumento da esterilidade das espiguetas verificado no M3 evidencia a ocorrência de estresse hídrico as plantas, durante a fase reprodutiva (na meiose ou na antese), agravando-se à medida que se elevaram os níveis de compactação. Esse resultado corrobora com os encontrados por Carvalho Junior (1987), Cusciol (2001) e Rodrigues (1998) que também observaram o aumento da esterilidade de grãos de arroz, decorrente de déficit hídrico, ocorrido durante a fase reprodutiva da planta de arroz. 


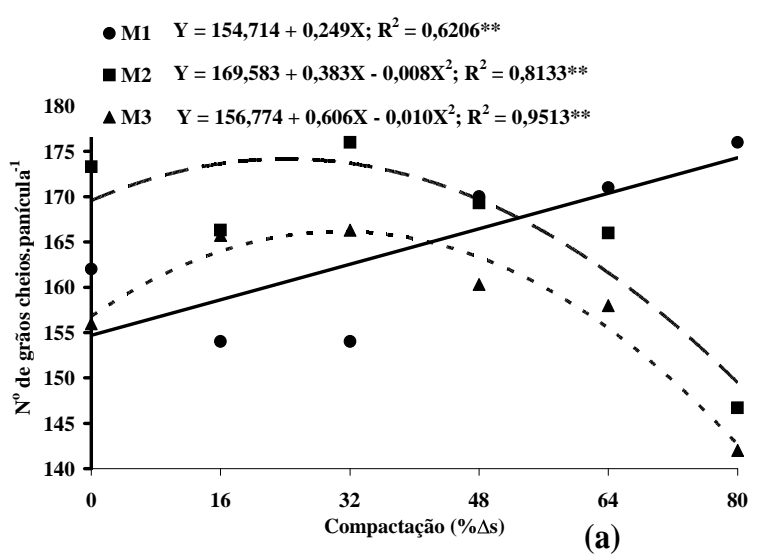

FIGURA 2 - Número de grãos cheios por panícula (a) e esterilidade de espiguetas (b) em função dos níveis de compactação e do manejo da água. Lavras-MG, 2004.

A massa de 1000 grãos não sofreu influência dos fatores testados, cuja média $(25,15 \mathrm{~g})$ manteve-se estável nos diferentes níveis de compactação e manejos de água. Esse resultado é condizente com os de Barreto \& Rojas (1987) e Medeiros et al. (1997), que ao avaliarem o comportamento do arroz sob diferentes manejos de água, também não constataram diferenças na massa de 1000 grãos obtidas entre os manejos. Segundo Yoshida (1981), a massa de 1000 grãos é uma característica varietal muito estável, pois é mais dependente do tamanho da casca do que de qualquer outro fator.

As médias da produtividade de grãos obtidas em função da interação níveis de compactação x manejos de água são mostrados na Figura 3. Comparando as médias obtidas entre os diferentes manejos de água, verifica-se que a produtividade de grãos foi favorecida pelos maiores teores de água no solo, independentemente dos níveis de compactação. Isso, deve-se ao incremento do número de panícula por vaso, cuja média do M1 $(24,9)$ superou em $19,3 \%$ a do M2 $(20,8)$ e em $23,3 \%$ a do M3 $(20,2)$, ao maior número de grãos cheios por panícula e a menor esterilidade de espiguetas nos ambientes com maior umidade. Esse resultado é semelhante aos obtidos por Barreto \& Rojas (1987), Crusciol (2001) e Sorato et al. (2002), que também observaram aumento da produtividade de grãos de arroz com a maior disponibilidade de água no solo, os quais atribuíram seus resultados à maior disponibilidade e a absorção de nutrientes proporcionadas pela maior disponibilidade de água no solo.

Por outro lado, a compactação do solo reduziu a produtividade de grãos em todos os manejos de água.

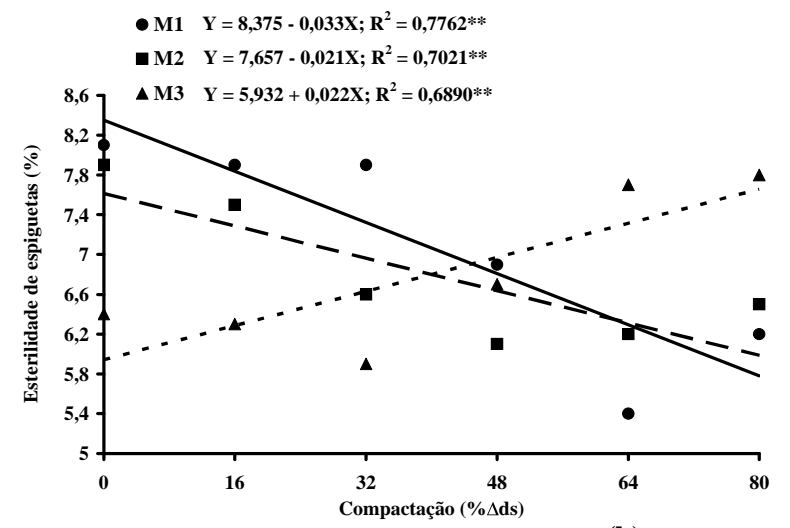

(b)
Portanto, houve uma associação inversa entre os níveis de compactação e a produtividade de grãos. Os efeitos da compactação sobre a produtividade de grãos, para os três manejos de água, ajustaram-se a modelos de regressão linear decrescente (Figura 3). Assim, para cada aumento de um por cento de variação na amplitude da densidade do solo, ocorreu uma redução na produtividade de grãos de 0,214 $\mathrm{g} \mathrm{vaso}^{-1}$ no $\mathrm{M} 1,0,427 \mathrm{~g}_{\text {vaso }}{ }^{-1}$ no $\mathrm{M} 2$ e $0,361 \mathrm{~g} \mathrm{vaso}^{-1}$ no $\mathrm{M} 3$.

Comparando as médias da produtividade de grãos (Figura 3) obtidas sob os níveis mínimo e máximo de compactação nos diferentes manejos de água (111,6 e 94,9

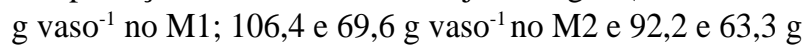
vaso $^{-1}$ no $\mathrm{M} 3$, respectivamente), verifica-se que, mesmo havendo redução da produtividade de grãos com o aumento da compactação, independentemente do manejo de água, a menor produtividade de grãos (94,9 g.vaso $\left.{ }^{-1}\right)$ obtida no nível máximo de compactação sob o M1 foi 2,5\% superior a maior média $\left(92,2\right.$ g.vaso $\left.{ }^{-1}\right)$ alcançada no solo não compactado sob o M3. Portanto, pode-se inferir que a produtividade de grãos de arroz foi mais influenciada pelos teores de água no solo do que pelos níveis de compactação.

Considerando o nível de compactação de $24 \%$ da $\Delta \mathrm{ds}$, que corresponde a ds $=1,17 \mathrm{~kg} \mathrm{dm}^{-3}$, ou seja, a densidade semelhante a que ocorre no campo sob o plantio direto para esse solo (amostra indeformada), ocorreria uma redução simulada na produtividade de grãos de $4,6 \%$ no M1, 10,6\% no M2 e 9,4\% no M3. Essa redução deve-se, dentre outros fatores, a diminuição do número de panículas vaso $^{-1}$, pois foi o componente de produção de grãos mais afetado pelos níveis de compactação. Por outro lado, a menor variação na produtividade de grãos, entre os diversos 
níveis de compactação, proporcionada pelo M1, explicase pelas menores restrições na disponibilidade e absorção de nutrientes e ao maior desenvolvimento do sistema radicular que atenuou a redução do número de panículas vaso $^{-1}$, favorecendo o número de grãos cheios panícula ${ }^{-1} \mathrm{e}$ a redução da esterilidade das espiguetas.

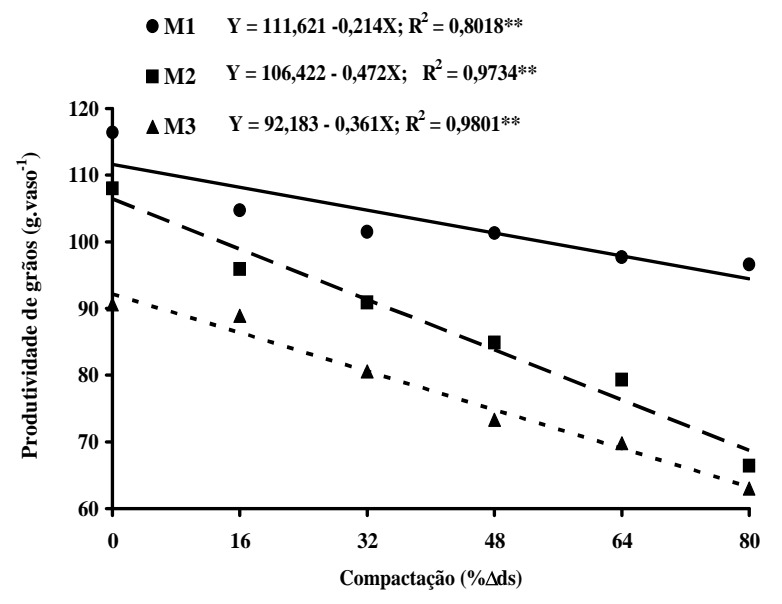

FIGURA 3 - Produtividade de grãos de arroz obtida em função dos níveis de compactação x manejo de água. UFLA, Lavras, MG, 2004.

Portanto, isso indica que, para o cultivo do arroz em várzeas com o solo saturado e, presumivelmente irrigado por inundação, a compactação do solo tem pouca influência sobre a produtividade de grãos. Pois a saturação e, ou, a inundação favorece a atividade fotossintética da cultura, a elevação do $\mathrm{pH}$, a disponibilidade e a absorção de nutrientes devido à redução e solubilização dos óxidos de ferro, incrementando a produção de massa seca da parte aérea, o número de panícula por área e a produtividade grãos (GOMES et al., 1985). Esses resultados são concordantes com os obtidos por Macedo et al. (1999) e Weber et al. (1999), que não constataram diferenças significativas na produtividade de grãos de arroz no sistema de preparo do solo convencional e plantio direto.

\section{CONCLUSÕES}

a) A compactação e a umidade do solo não interferem na massa de 1000 grãos.

b) A compactação do solo promove redução do número de panículas vaso $^{-1}$, mas em níveis moderados propicia o aumento do número de grãos cheios por panícula ${ }^{-1}$. c) A umidade mais elevada do solo favorece a produtividade de grãos através do número de panículas por vaso, do número de grãos cheios por panícula ${ }^{-1} \mathrm{e}$ da menor esterilidade das espiguetas.

d) A disponibilidade de água no solo limita mais acentuadamente a produtividade de grãos do que a compactação per si.

\section{REFERÊNCIAS BIBLIOGRÁFICAS}

ALVARENGA, R. C.; COSTA, L. M.; MOURA FILHO, W.; REGAZZI, A. J. Crescimento de leguminosas em camadas de solo compactadas artificialmente. Revista Brasileira de Ciência do Solo, Campinas, v. 20, n. 2, p. 319-326, maio/ ago. 1996.

BARRETO, J. R. R.; ROJAS, P. Manejo de água y nitrogeno en arroz riego en el ville del cuaca. Acta Agronomica, Palmira, v. 37, n. 1, p. 22-34, 1987.

CARVALHO JUNIOR, A. C. de. Efeito da adubação potássica em cultivares do arroz (Oryza sativa $\mathrm{L}$.) de sequeiro sob déficit hídrico, em solo sob cerrado. 1987. 160 f. Dissertação (Mestrado) - Escola Superior de Agricultura de Lavras, Lavras, 1987.

COSTA, J. P. V. da. Fluxo de difusivo de fósforo e de potássio em Latossolos. Viçosa: UFV, 1998. 67 p.

CRUSCIOL, C. A. C. Crescimento radicular, nutrição e produção de cultivares de arroz de terras altas em função da disponibilidade hídrica e de fósforo. $2001.111 \mathrm{f}$. Tese (Livre docência) - Universidade Estadual Paulista, Botucatu, 2001.

CRUSCIOL, C. A. C.; MACHADO, J. R.; ANDREOTTI, M.; ARF, O.; RODRIGUES, R. A. F. Desenvolvimento das plantas de arroz irrigado por aspersão em função do manejo da água. In: REUNIÃO DA CULTURA DO ARROZ IRRIGADO, 22., 1997, Balneário de Camboriú. Anais... Balneário de Camboriú: [s.n.], 1997. p. 262264.

EMPRESA BRASILEIRA DE PESQUISA AGROPECUÁRIA. Centro Nacional de Pesquisa de Solos. Manual de métodos de análise de solos. 2. ed. Rio de Janeiro, 1997. 212 p. (Documentos, 1). 
GOMES, A. da S.; VAHL, L. C.; PAULETTO, A. E.; PORTO, V. H. da F.; GONZALES, B. D. Fundamentos para a cultura do arroz irrigado. In: EMPRESA BRASILEIRA DE PESQUISA AGROPECUÁRIA. Centro de Pesquisa Agropecuária de Terras Baixas de Clima Temperado. Fundamentos para a cultura do arroz irrigado. Campinas: Fundação Cargill, 1985. p. 251-274.

GROSS, M. R.; RIBEIRO, G. J. T.; SCHMIDT, P. A.; CORREAA, J. B. D.; LEITE, G. M. V.; SILVEIRA, T. Comportamento do rendimento de forrageiras em função da compactação em latossolo vermelho distroférrico típico. In: CONGRESSO BRASILEIRO DE CIÊNCIA DO SOLO, 29., 2003, Ribeirão Preto-SP. Anais... Ribeirão Preto: UNESP, 2003. CD-ROM.

GUIMARÃES, C. M.; MOREIRA, J. A. A. Compactação do solo na cultura do arroz de terras altas. Pesquisa Agropecuária Brasileira, Brasília, v. 36, n. 4, p. 703-707, abr. 2001.

GUIMARÃES, C. M.; STONE, L. F.; MOREIRA, J. A. A. Compactação do solo na cultura do feijoeiro: II. efeito sobre o desenvolvimento radicular e da parte aérea. Revista Brasileira de Engenharia Agrícola e Ambiental, Campina Grande, v. 6, n. 2, p. 213-218, maio/ago. 2002.

HOFFMANN, C.; JUNGK, A. Growth and phosphorus supply of sugar beet as affected by soil compaction and water tension. Plant and Soil, Dodrecht, v. 176, n. 1, p. 1525, Sept. 1995.

HOOQUE, M. M.; KOBATA, T. Effect of soil compaction on the grain yield of rice (Oryza sativa $\mathrm{L}$ ) under waterdeficit stress during the reproductive stage. Plant Production Science, Matsue, v. 3, n. 3, p. 316-322, 2000.

KLUTHCOUSKI, J. Efeito de manejo em alguns atributos de um latossolo roxo sob cerrado e nas características produtivas de milho, soja, arroz e feijão, após oito anos de plantio direto. 1998. 179 f. Tese (Doutorado em Fitotecnia) -Escola Superior de Agricultura Luiz de Queiroz, Piracicaba, 1998.

LEITE, G. M. V.; RIBEIRO, G. J. T.; GROSS, M. R.; SCHMIDT, P. A.; CORRÊA, J. B. D.; SILVEIRA, T. Influência da compactação na germinação e desenvolvimento do arroz em três classes de solo. In: CONGRESSO BRASILEIRO
DE CIÊNCIA DO SOLO, 29., 2003, Ribeirão Preto-SP. Anais... Ribeirão Preto: UNESP, 2003. CD-ROM.

MACEDO, V. R. M.; LOPES, M. S.; CORRÊA, N. I.; ANDRES, A.; LOPES, S. I. G.; SOUSA, P. R. de. Avaliação de sistemas de cultivo de arroz irrigado: parâmetros de rendimento. In: CONGRESSO BRASILEIRO DE ARROZ IRRIGADO, 1.; REUNIÃO DA CULTURA DO ARROZ IRRIGADO, 23., 1999, Pelotas. Anais... Pelotas: EMBRAPA Clima Temperado, 1999. p. 269-271.

MEDEIROS, R. D. de; GHELFI FILHO, H.; DARIO, G. J. A.; BOTREL, T.; COSTA, M. C. Efeito do manejo da água e de herbicidas na cultura do arroz (Oryza sativa $\mathrm{L}$ ) irrigado. Irriga, Botucatu, v. 2, n. 1, p. 38-49, 1997.

RIBEIRO, G. J. T.; CORRÊA, J. B. D.; LEITE, G. M. V.; MOURA, F. P.; SOARES, A. A. Compactação e sua influência no desenvolvimento e produção de arroz, em três classes de solos. In: CONGRESSO BRASILEIRO DE CIÊNCIA DO SOLO, 29., 2003, Ribeirão Preto-SP. Anais... Ribeirão Preto: UNESP, 2003. CD-ROM.

RIBEIRO, M. A. V. Resposta da soja e do eucalipto a fósforo em solos de diferentes texturas, níveis de densidade e de umidade. 1999. 71 p. Tese (Doutorado) - Universidade Federal de Lavras, Lavras, 1999.

RODRIGUES, R. A. F. Efeitos do manejo de água nas características fenológicas e produtivas do arroz (Oryza sativa $\mathrm{L}$ ) cultivado em condições de sequeiro sob irrigação por aspersão. 1998. 75 f. Tese (Doutorado) - Universidade Estadual Paulista, Botucatu, 1998.

SÉGUY, L.; BOUZINAC, S.; MARONEZZI, A. C.; TAFFAREL, V.; TAFFAREL, J. Plantio direto do arroz de sequeiro de alta tecnologia na zona tropical úmida do centro-norte do Mato Grosso. Informações Agronômicas, Piracicaba, n. 86, p. 1-28, jun. 1999. Encarte técnico.

SILVEIRA, P. M. da. Densidade do solo e micronutrientes em arroz de terras altas. In: CONGRESSO DA CADEIA PRODUTIVA DO ARROZ, 1.; REUNIÃO NACIONAL DE PESQUISADEARROZ-RENAPA, 7., 2002, Florianópolis. Anais... Florianópolis: EMBRAPA Arroz e Feijão, 2002. p. 538-539. 
SMUCKER, A. J. M.; ERICKSON, A. E. Tillage and compactive modifications of gaseous flow and aeration. In: LARSON, W. E.; ALLAMARAS, R. R.; VOORHEES, W. B.; GUPTA, S. C. (Eds.). Mechanics related process in structured agricultural soils: nato applied sciences. Amesterdam: Kluwer Academic, 1989. p. 205-221.

SORATO, R. P.; RODRIGUES, R. A. F.; ARF, O. Manejo de água em cultivares de arroz irrigado por aspersão no sistema de plantio direto. In: CONGRESSO DA CADEIA PRODUTIVA DE ARROZ, 1.; REUNIÃO NACIONAL DE PESQUISADEARROZ-RENAPA, 7., 2002, Florianópolis, SC. Anais... Santo Antônio de Goiás: EMBRAPA Arroz e feijão, 2002. p. 369-372. (Documentos, 134).

STIRZAKER, R. J.; PASSIOURA, J. B.; WILMS, Y. Soil structure end plant growth: impactof bulk density and biopores. Plant and Soil, Dordrecht, v. 185, n. 1, p. 151-162, 1996.
STONE, L. F.; GUIMARÃES, C. M.; MOREIRA, J. A. A. Compactação do solo na cultura do feijoeiro: I. nas propriedades físico-hídricas do solo. Revista Brasileira de Engenharia Agrícola e Ambiental, Campina Grande, v. 6, n. 2, p. 213-218, maio/ago. 2002.

WEBER, L.; MAECHEZAN, E.; CARLESSO, R.; SEGABINAZZI, T. Desempenho de cultivares de arroz irrigado em diferentes sistemas de cultivo. In: CONGRESSO BRASILEIRO DE ARROZ IRRIGADO, 1.; REUNIÃO DA CULTURA DO ARROZ IRRIGADO, 23., 1999, Pelotas. Anais... Pelotas: EMBRAPA Clima Temperado, 1999. p. 296-298.

YOSHIDA, S. Factors that limit the growth and yields of upland rice. In: INTERNATIONAL RICE RESEARCH INSTITUTE. Major research in upland rice. Los Baños, 1975. p. 46-71.

YOSHIDA, S. Fundamentals of rice science. Los Baños: International Rice Research Institute, 1981. 269 p. 